\title{
Positron and positronium annihilation patterns in zeolites and bulk ceramics
}

\author{
Zs. Kajesos ${ }^{*}, 1$, C. Kosanović ${ }^{2}$, L. Liszkay ${ }^{1}$, P. Major ${ }^{1}$, L. Lohonyai ${ }^{1}$, P. Zalán ${ }^{1}$, K. Lázár ${ }^{3}$, \\ S. Bosnar ${ }^{2}$, B. Subotić ${ }^{2}$, D. Bosnar ${ }^{4}$, K. Havancsák ${ }^{5}$, P.M. Gordo ${ }^{6}$, and N. Tomašić ${ }^{7}$ \\ ${ }^{1}$ KFKI Res. Inst. for Part. Nucl. Physics, P.O. Box 49, 1525 Budapest 114, Hungary \\ 2 Div. of Mater. Chem., Ruđer Bošković Institute, Bijenička 54, P.O. Box 180, Zagreb, Croatia \\ 3 Inst. of Isotopes HAS, P.O. Box 77, 1525 Budapest, Hungary \\ ${ }^{4}$ Dept. of Physics, University of Zagreb, Bijenička 32, Zagreb, Croatia \\ 5 Dept. of Materials Physics, Eötvös Univ., Pázmány Péter sétány 1/A, 1117 Budapest, Hungary \\ ${ }^{6}$ ICEMS, Dept. of Physics, University of Coimbra, Coimbra 3004-516, Portugal \\ ${ }^{7}$ Inst. of Mineralogy and Petrography, University of Zagreb, Horvatovac bb, 10000 Zagreb, Croatia
}

Received 23 July 2006, accepted 4 June 2007

Published online 13 August 2007

PACS 36.10.Dr, 61.43.Gt, 61.72.Qq, 78.70.Bj

Positron lifetime (LT) measurements have revealed that in porous media the annihilation pattern is probably dominated by a near-saturation level trapping both for the positron and the positronium as well, which masks the contribution from the "free annihilation", i.e., annihilation from delocalised positrons. In this work we compare positron lifetime spectra of crystalline zeolites with bulk ceramic materials fabricated by sintering from the same constituents as the zeolites and analyse common features and differences between them. For the dense ceramic samples the contribution from long-living components to the annihilation pattern is substantially lower than that for the zeolites. The results are analysed with the aim to extract new knowledge for the zeolites and for the sensitivity limits for free volume studies in ceramics.

() 2007 WILEY-VCH Verlag GmbH \& Co. KGaA, Weinheim

1 Introduction By now, positron annihilation techniques (PAT) have become extensively used for structural investigation of solids. In the several decades of the evolution of PAT, the interest has shifted somewhat from electronic structural studies to the investigation of structural imperfections where positron trapping has played an important role. In contrast to bulk solids, porous media present a more complex picture: positron lifetime (LT) data revealed the coexistence of annihilation modi with long lifetime components, ascribed to the annihilation of orthopositronium (o-Ps) in various free or confined states [1$3]$. If trapped, Ps remains and decays in the trap. The simple quantum-well model $[4,5]$ - correlating the o-Ps lifetime to the size of the trapping sites where it annihilates - was applied with success. and was developed further recently (e.g., [6]), taking into account non-spherical geometry, too. The long lifetime values indicate a low interaction of o-Ps with its surroundings and call attention to the necessity to appropriately record also the $3 \gamma$-decaying modes in LT spectroscopy, customarily tuned to observe $2 \gamma$ annihilation events only. The o-Ps states are sensitive to additives (e.g., surface-bound ions, gases) which may transform the long-living states into other, shorter-living ones, annihilating via $2 \gamma$-annihilation. It has also been shown $[7,8]$ that changes in the $3 \gamma / 2 \gamma$-ratio may also strongly influence the PAT parameters due to the changes induced in the detection efficiency and sophisticated corrections are necessary.

\footnotetext{
* Corresponding author: e-mail: kajcsos@rmki.kfki.hu
} 
Among the porous substances, zeolites have a special role. The high Ps yield in them facilitated studies on the applicability of PAT for structural investigations. Extensive work (e.g., [9, 10]) with LT and Doppler-effect technique (DE), carried out in the last two decades has shown correlations between the prevalence and the characteristics of long-living annihilation modes with the water and gas content, technological parameters, etc. Encouraging success has been achieved in theoretical modelling of positronium states in porous media [12] but still many open questions remained [13]. It has been concluded [14], that a near-saturation level trapping of positrons and positronium probably dominates the annihilation pattern.

Zeolites, porous crystalline aluminosilicates characterized by a network of interconnected channels and cavities with mobile non-framework cations located at specific sites, are synthesized from aluminosilicate gels by hydrothermal treatment. The remaining water can be evaporated by vacuum heating, and micropore volumes become accessible. Recently, LT measurements have been started to study the potential of PAT to follow the progress of crystallization of zeolites out of their amorphous precursors. The promising results [15] have drawn attention to the fact that the "bulk-specific" lifetime parameters cannot be established unambiguously as the free annihilation contribution is obscured by the trapping.

We report here our preliminary LT results on various types of crystalline zeolites and on bulk ceramic materials made from the same constituents as the zeolites. The annihilation patterns for those two classes of samples were compared with a view to extract new knowledge for the zeolites.

2 Experimental Based on earlier experience, A-type zeolites were prepared, treated and analysed in Zagreb. Partial exchange of the original $\mathrm{Na}^{+}$ions from zeolite A with $\mathrm{NH}_{4}^{+}, \mathrm{Li}^{+}, \mathrm{K}^{+}, \mathrm{Cs}^{+}, \mathrm{Rb}^{+}$ions from solutions was carried out as described in $[16,17]$. Ageing (i.e., the waiting time from the mixing of reagents at room temperature (RT) until heating to the crystallization temperature) shortens the crystallization time, increases the growth rate [18] and results in larger numbers of smaller product crystals [19]. The exchanged zeolites were kept in a desiccator with saturated $\mathrm{NaCl}$ solution for $24 \mathrm{~h}$ before analyses. Some $0.5-0.7 \mathrm{~g}$ of the zeolite powders served to press tablets (with a diameter of $13 \mathrm{~mm}$ ) at $7.540 \mathrm{MPa}$. The crystalline samples $\left(\mathrm{NaA}, \mathrm{LiA}, \mathrm{KA}, \mathrm{CsA}, \mathrm{RbA}, \mathrm{NH}_{4} \mathrm{~A}\right)$-both as loose powder and as tablets- were heated isothermally in a chamber furnace to their respective exothermic peak temperature $T_{p}$ and kept there for several hours. All samples were characterized by powder X-ray diffractometry, thermogravimetry and FT-IR spectroscopy, pressing did not result in any changes.

A number of samples with different compositions were prepared with the goal to provide specimens for future extended studies as well. Only $\mathrm{NaA}$ zeolite will be considered here, where the zeolite structure was achieved through successive heat treatment at $373 \mathrm{~K}$. Ceramic samples (the ones studied here are shown in Table 1) were produced at a high-temperature bake-out, remained partly amorphous in some cases.

Table 1 The collection of ceramics samples for LT studies.

\begin{tabular}{lll}
\hline Sample & Heat treatment $\left(3 \mathrm{~h}\right.$ at $\left.\mathrm{T}_{\mathrm{p}}{ }^{\circ} \mathrm{C}\right)$ & Characterization \\
\hline $\mathrm{NaA}$ & 900 & Low-carnegieite \\
$\mathrm{LiA}$ & 822 & Amorphous \\
$\mathrm{KA}$ & 964 & Amorphous \\
$\mathrm{CsA}$ & 1050 & Mix of Pollucite/Caesium sodium silicate \\
$\mathrm{RbA}$ & 1055 & Rubidium aluminum silicate \\
$\mathrm{NH}_{4} \mathrm{~A}$ & 1000 & Mullite $\mathrm{Al}_{6} \mathrm{Si}_{2} \mathrm{O}_{3}+$ amorphous $\mathrm{SiO}_{2}$ \\
\hline
\end{tabular}

For PAT studies, "zeolite" and "ceramic" samples were processed the same way and were prepared sandwiching the ${ }^{22} \mathrm{Na}$ source $(0.5-2.0 \mathrm{MBq}$ activity between thin Kapton, Ti or Al foils), wrapped in Alfoil. Placing the samples into a miniaturized Al sample holder, LT measurements were first performed in air, subsequently in vacuum at RT, and finally after a heat treatment in vacuum in the temperature range 450-550 K. The fast-fast coincidence LT spectrometer (featuring XP 2020 URQ photomultipliers 
equipped with $25 \mathrm{~mm}$ x $25 \mathrm{~mm} \mathrm{NE} 111$ and $\mathrm{BaF}_{2}$ scintillators and ORTEC electronics) assured efficient recording of $3 \gamma$ - events [10], with cca. 270 ps FWHM time-resolution for ${ }^{60} \mathrm{Co}$. LT spectra were recorded in a Microfast 16k PC MCA. For samples with long lifetime contributions a range of $0.5-1 \mu$ s was selected, for the "short lifetime" cases this was reduced to 100 ns. The time calibration values were $29 \mathrm{ps} / \mathrm{ch}, 61 \mathrm{ps} / \mathrm{ch}$ and $6.5 \mathrm{ps} / \mathrm{ch}$, respectively. Integral counts of $2 \times 10^{6}-1 \times 10^{7}$ were collected. Evaluation of the LT spectra (with appropriate source corrections) was carried out by using the LT v.9 fitting program [20]. The reproducibility was found satisfactory.

3 Results: discussion and conclusions LT spectra show the "survival" and not the "birth" fractions of the components [10-15]. A satisfactory LT fit for zeolites requires at least four lifetime components: $0.2-0.5 \mathrm{~ns}$ combining p-Ps and $\mathrm{e}^{+}$annihilations, $1-4 \mathrm{~ns}$ for o-Ps probably trapped in microvoids, $10-90$ ns for o-Ps decaying in channels of the zeolites and 100-135 ns for o-Ps decaying in intergrain space. The evolution of the long components shows a surprising proliferation of the trapping sites responsible for $\tau_{3}$ at the expense of $\mathrm{I}_{4}$, as shown in Fig. 1, probably indicating the decreasing chance that with an increasing number of the zeolite pores the o-Ps may diffuse far and reach more extended traps where longer lifetimes may occur. Water degassing does not influence this process much. The free volume parameters defined from the long lifetimes with the Tao-Eldrup model $(\mathrm{R}=8.5-13.8 \mathrm{~nm})$ show that mesoporous defects may also be present $[12,14]$.
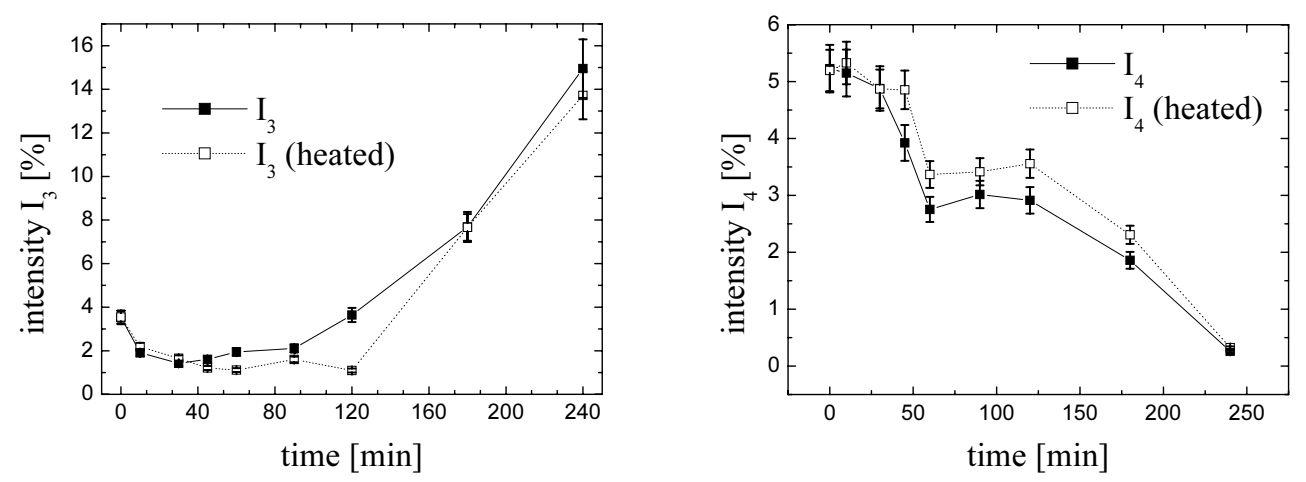

Fig. 1 Long component intensities $v s$. heat treatment duration are shown for gel $\rightarrow \mathrm{NaA}$ zeolite transformation.

Table 2 shows a collection of LT results. For ceramic samples, a reduction in the long components (with noticeably shorter lifetimes and lower intensities) was expected and was found indeed. For the comparatively low relative intensity of the long components here, our estimations have shown that the systematic errors remain below 2 percent for the intensity of $\mathrm{I}_{4}$. Furthermore, the three-component fit also gave acceptable results, indicating that the trapping sites yielding in the longest lifetimes are missing in the more dense structure of the ceramics. The short lifetime region could be further scrutinized in order to establish possible correlation with the metallic structural ions.

However, in this part of the LT spectra, saturation-near positron trapping may also occur, therefore samples with known low and high "defect" concentration would be highly desirable. The true intensity ratios between various annihilation channels existing in complex micro- and nanoporous media could be better estimated by the combined application of the various PAT methods. A distribution of lifetime values instead of discrete lifetime components should also be considered in future studies. Slow positron measurements could help to clarify some questions in connection with surface phenomena.

This preliminary selection of samples shows that this line of investigation may give new information and a more extensive comparison of respective zeolite-ceramic sample pairs could help to pinpoint the steps in the formation and decay of positronium in porous media. This goal may help to extend the application of PAT to the study of hidden surfaces in nanostructured materials and it is in progress. 
Table 2 Typical LT parameters, given for the NaA zeolite in various stages of transformation from the gel and for some of the ceramic samples. (a=amorphous, errors in intensities amount to $5 \%$, relative).

\begin{tabular}{|l|c|c|c|c|l|l|l|l|}
\hline \multicolumn{1}{|c|}{ Sample } & $\tau_{1}(\mathrm{~ns})$ & $\tau_{2}(\mathrm{~ns})$ & $\tau_{3}(\mathrm{~ns})$ & $\tau_{4}(\mathrm{~ns})$ & $\mathrm{I}_{1}(\%)$ & $\mathrm{I}_{2}(\%)$ & $\mathrm{I}_{3}(\%)$ & $\mathrm{I}_{4}(\%)$ \\
\hline $\mathrm{NaA}$ (gel) & $0.27 \pm 0.01$ & $0.79 \pm 0.02$ & $6.97 \pm 0.09$ & $61.57 \pm 1.2$ & 67.6 & 23.6 & 3.5 & 5.3 \\
\hline $\mathrm{NaA}(\mathrm{zeol}$ ) & $0.26 \pm 0.01$ & $0.60 \pm 0.02$ & $3.41 \pm 0.05$ & $105.3 \pm 1.9$ & 45.2 & 40.7 & 13.2 & 0.3 \\
\hline \multicolumn{1}{|c|}{$\mathrm{NaA}$} & $0.18 \pm 0.01$ & $0.45 \pm 0.02$ & $1.55 \pm 0.04$ & $9.86 \pm 0.09$ & 57.3 & 38.8 & 3.2 & 0.7 \\
\hline $\mathrm{LiA}(\mathrm{a})$ & $0.19 \pm 0.01$ & $0.46 \pm 0.02$ & $1.11 \pm 0.03$ & $9.42 \pm 0.11$ & 22.0 & 2.2 & 3.1 & 18.0 \\
\hline $\mathrm{KA}(\mathrm{a})$ & $0.16 \pm 0.01$ & $0.37 \pm 0.02$ & $1.02 \pm 0.02$ & $3.83 \pm 0.05$ & 27.1 & 52.6 & 19.0 & 1.3 \\
\hline $\mathrm{CsA}$ & $0.19 \pm 0.01$ & $0.46 \pm 0.2$ & $1.32 \pm 0.02$ & $11.65 \pm 0.17$ & 41.6 & 44.5 & 12.9 & 1.0 \\
\hline $\mathrm{RbA}$ & $0.22 \pm 0.01$ & $0.54 \pm 0.02$ & $1.36 \pm 0.03$ & $14.51 \pm 0.16$ & 48.2 & 41.6 & 9.4 & 0.8 \\
\hline $\mathrm{NH}_{4} \mathrm{~A}$ & $0.22 \pm 0.01$ & $0.51 \pm 0.01$ & $1.33 \pm 0.02$ & $13.68 \pm 0.15$ & 44.8 & 41.2 & 13.2 & 0.8 \\
\hline $\mathrm{Li}$ & $0.21 \pm 0.01$ & $0.43 \pm 0.02$ & $1.06 \pm 0.03$ & --------- & 39.9 & 52.0 & 8.1 & ------ \\
\hline $\mathrm{KA}$ & $0.22 \pm 0.01$ & $0.51 \pm 0.02$ & $1.18 \pm 0.04$ & $15.70 \pm 0.21$ & 49.7 & 40.9 & 8.8 & 0.6 \\
\hline
\end{tabular}

Acknowledgements Our PAT studies of porous media were initiated in a Hungarian-French bilateral cooperation and were continued and supported later within a Hungarian Portuguese (P-23/03) and a Hungarian-Croatian (HR1/2004) bilateral research agreement. Contributions through research grants of OTKA (Hungarian Research Fund, Grant Nos. T029215, 030327, T032029, T032249, T046238, W15585, W15722) and in Croatia by the Ministry of Science, Education and Sports, contract Nos. 0119259, A679078 and 0098060 were essential. Discussions with Dr. L. Varga, assistance in sample preparation by Dr. B. Molnár and Cs. Bogdány are gratefully acknowledged.

\section{References}

[1] R. Paulin and G. Ambrosino, J. Phys. 29, 263 (1968)

[2] M. Debowska, J. Ch. Abbé, and G. Duplâtre, phys. stat. sol. (b), 146, 91 (1988).

[3] G. Duplâtre, Zs. Kajcsos, I. Billard, L. Liszkay, K. Lázár, L. Lohonyai, H. K. Beyer, P. Caullet, and J. Patarin, Stud. Surf. Sci. Catal. 125, 277 (1999).

[4] S.J. Tao, J. Chem. Phys. 56(11), 5499 (1972).

[5] M. Eldrup, D. Lightbody, and J. N. Sherwood, Chem. Phys. 63, 51 (1981).

[6] T. Goworek, K. Ciesielski, B. Jasinska, and J. Wawryszczuk, Radiat. Phys. Chem. 58, 719 (2000).

[7] C. Dauwe, Mater. Sci. Forum, 105-110, 1857 (1992).

[8] Zs. Kajcsos, L. Liszkay, L. Varga, K. Lázár, G. Brauer, and C. Dauwe, Mater. Sci. Forum 175-178, 959 (1995)

[9] M. A. Alam, H. M. Fretwell, J. A. Duffy, A. P. Clarke, and S. B. Dugdale, J. Radioanal. Nucl. Chem. 210(2), 255 (1996).

[10] L. Liszkay, Zs. Kajcsos, G. Duplâtre, K. Lázár, G. Pál-Borbély, and H. K. Beyer, Mater. Sci. Forum 363-365, 377 (2001).

[11] Zs. Kajcsos, L. Liszkay, G. Duplâtre, L. Varga, L. Lohonyai, F. Pászti, E. Szilágyi, K. Lázár, E. Kótai, G. PálBorbély, H. K. Beyer, P. Caullet, J. Patarin, M. E. Azenha, P. M. Gordo, C. Lopes Gil, A. P. de Lima, and M. F. Ferreira-Marques, Acta Phys. Pol. A 107, 729 (2005).

[12] A. L. R. Bug, M. Muluneh, J. Waldman, and P. A. Sterne, Mater. Sci. Forum 445/446, 375 (2004).

[13] Zs. Kajcsos, G. Duplâtre, L. Liszkay, I. Billard, A. Bonnenfant, E. Azenha, K. Lázár, G. Pál-Borbély, P. Caullet, J. Patarin, and L. Lohonyai, Radiat. Phys. Chem. 58, 709 (2000).

[14] Zs. Kajcsos, L. Liszkay, G. Duplâtre, K. Lázár, L. Lohonyai, L. Varga, P. M. Gordo, A. P. de Lima, C. Lopes de Gil, M. F. Ferreira Marques, D. Bosnar, S. Bosnar, C. Kosanovic, and B. Subotic, Radiat. Phys. Chem. 76, 231 (2007).

[15] S. Bosnar, C. Kosanović, B. Subotić, D. Bosnar, Zs. Kajcsos, L. Liszkay, L. Lohonyai, B. Molnár, and K. Lázár, Radiat. Phys. Chem. 76, 252 (2007).

[16] C. Kosanović, A. Čižmek, B. Subotić, I. Šmit, M. Stubičar, and A. Tonejc, Zeolites 15, 632 (1995).

[17] C. Kosanović, A. Čižmek, B. Subotić, and I. Šmit, Thermochim. Acta 317, 25 (1998).

[18] P. S. Singh, T.L. Dowling, J.N. Watson, and J.W. White, Phys. Chem. Chem. Phys. 1, 4125 (1999).

[19] C. S. Cundy, Stud. Surf. Sci. Catal. 157, 65 (2005).

[20] J. Kansy, Nucl. Instrum. Methods Phys. Res. A 374(2), 235 (1996). 